\title{
Modelling the seasonal climate variability and its effects on vintage wines from Marlborough, NZ
}

\author{
Subana Shanmuganathan and Ana Perez Kuroki \\ Geoinformatics Research Centre, \\ School of Computing and Mathematical Sciences, \\ Auckland University of Technology \\ New Zealand
}

\author{
Ajit Narayanan and Philip Sallis \\ Geoinformatics Research Centre, \\ School of Computing and Mathematical Sciences, \\ Auckland University of Technology \\ New Zealand
}

\begin{abstract}
The paper presents interim results of ongoing research on the application of dataltext mining methodologies investigated to modelling the seasonal climate variability and its effects on the world famous Marlborough vintage wines. The research efforts are an extension to the investigation thus far conducted on modelling the effects of seasonal climate variability on Kumeu wines and all the sub-projects contribute to an overarching project which is aimed at developing a scheme/ suitable set of procedures for the identification and characterisation of wines produced from New Zealand's major wine regions. The distinctive New Zealand wine styles along with the regions from where the wines come from are initially elaborated. The major issues regarding the topic are; firstly, there is no single method that could be considered as the best way to establish the links between precise independent (climatel weather) and the rather imprecise dependent (subjective wine quality) data sets. Secondly, the data on New Zealand wine quality is not sufficient enough to perform any conventional rigorous analytical approaches as data on wine quality spans only a decade, hence we look at datal text mining methods and a combination of explorative and statistical data analysis methodologies to resolve the issues. Following a brief outline on the methods investigated and results achieved in the Kumeu wine case study, the paper presents the new methods and approaches explored with Marlborough wines produced from 1996 to 2007. Finally, wine descriptors that are found to be linked with wine quality and therefore considered as correlated to the regional climatic conditions experienced in different wine regions of $\mathrm{New}$ Zealand, are discussed.
\end{abstract} words)

Keywords-component; formatting; style; styling; insert (key

\section{INTRODUCTION}

The quality of a vintage wine depends on the climate, the seasonal weather conditions that ripened the grapes as much as the winemaker experience and talent. This has been welldocumented in literature as seen in (1) (2). But knowledge on "how" and the "precise" weather conditions that affect the grape composition and the ripening process is fragmented (3). The major reason for this being lack of consistent data on wine quality to scientifically validate the anecdotal evidence by establishing the correlation/s between the two vital sets of factors, namely, the wine quality which is arguably a subjective issue when compared with the more precise and readily available weather data. This is especially the case with wines produced from most of the new world wine producing countries, such as New Zealand, Australia, Chile and South
Africa. However, in recent years, the interest in scientifically understanding the long- and short-term climate change effects on viticulture has been significant in both old as well as new world wine producing countries to improve vineyard operations and grape wine production. Nonetheless the lack of consistent data makes the modelling of climate change effects on grapevine growth, phenology and wine quality difficult using conventional methodologies.

In view of the above facts, researchers at AUT's Geoinformatics Research Centre (GRC) began investigating into experimenting with approaches that are generally referred to as other than the rigorous statistical data analysis methodologies to modelling the influence of weather conditions on the quality of vintages produced from different wine regions of New Zealand. The ultimate aim of this effort is to find a set of ideal features that can be used for the identification and characterisation of vintages produced from New Zealand's major wine regions under different seasonal weather conditions (4). Section II gives an outline on the results obtained with approaches already investigated using vintage ratings, sommelier comments (5) and grape yield (6) from Kumeu River Wines against local weather conditions. Section III looks at Marlborough wine and climate data being used in the research, following which results and future direction of this research are briefly outlined.

\section{CLIMATE EFFECTS ON WINES OF DIFFERENT VINTAGES}

Recent research in modelling the effects of seasonal climate variability on grapevine phenology, berry composition and wine quality showed that of the many factors, weather as the main influencing one at this temporal scale (7).

\section{A. Year-to year-variability in climate and its effects on wine}

In viticulture, it is believed that factors responsible for the vintage-to-vintage variability and in turn on the quality of grapes produced in that season, could be classified into two broader categories, namely terroir (climate, soil and location related) and cultiva (or variety). Of these two, the influence of terroir factors is described to be the major at this temporal scale. Research by van Leeuwen (8) found the proportions (in percentage) exerted by different factors and accordingly (50\%) was derived to be by climate, $(25 \%)$ by soil and $(10 \%)$ by cultivar. Hence, the research concluded climate as the major 
influencing factor and its affects being described as realised specifically through vine water balance status. The study looked at the influences of all variables (from terroir and cultiva) simultaneously on vintage-to-vintage vine development and berry composition. Non irrigated vitis vinifera was studied on gravelly soil (with heavy clay subsoil and sandy soil, and water table within the reach of roots). Merlot, Cabernet franc and Cabernet Sauvignon were the varieties used in the study. The climate variables used consisted of maximum and minimum temperatures, degree days (base of $10^{\circ} \mathrm{C}$ ), sunshine hours, ETo, rainfall, and water balance for a four year period from 1996 to 2000. Similarly, (9) (10) studied the seasonal climate effects on grapevine phenology and wine quality, and concluded that the temperature and weather related factors as the main deterministic factor/s.

\section{B. Year-to-year variability and its effects on Kumeu wines}

The initial results of the analysis carried out using 30 Kumeu (in northern New Zealand) wines showed the correlations between yearly total of 12 std deviation in monthly average temperatures and wine descriptor frequencies of 12 grouped descriptors extracted from sommelier comments given for the 30 wines produced during 1997-2006 (8). The wine descriptors were grouped using the WEBSOM approach to reduce the 51 descriptors into 12 groups. The WEBSOM $^{1}$ of 45 nodes was created with 51 descriptors and a commercial software package viscovery.

An interesting observation made from this study was that year 1998, with the highest ssd/mean within the period analysed consisted of high descriptor frequencies for clusters C2, C3, C6 and C10 descriptors. Meanwhile, year 2002 with the lowest ssd/mean temperature consisted of higher frequencies for $\mathrm{C} 5, \mathrm{C} 8$ and $\mathrm{C} 11$ descriptors. Discriminant analysis ran on the data set produced 11 words (underlined) as contributing factors in determining the variable vintage (or year considered as a dependent variable on the 11 descriptors). $\mathrm{C} 1$ descriptors were present in all years. The model correctly classified $76.7 \%$ of original grouped cases and $50.0 \%$ of crossvalidated grouped cases (30 cases in total). (ssd/meant: standard deviation of daily mean temperature for the growing season (Sep.-April)). Temperature data for the study was obtained from National Institute for Water and Atmospheric Research (NIWA).

\section{THE METHODOLOGY}

The research elaborated upon in this paper initially looked at different non conventional methods for modelling the correlations between wine descriptors of 778 Marlborough vintages and their ratings for studying the correlations between wine descriptor/ ratings and the seasonal weather conditions. The following are the steps of the methodology adopted here:

\footnotetext{
1 WEBSOM: The WEBSOM method provides an approach to organise a textual document collection onto a graphical map display with an facilitates to browse the document collection. The approach allows for content-directed search within the collection. Initially each document is encoded into a histogram of word categories that are used by the self-organizing map (SOM) algorithm to create a map based on the similarities in the contexts of the words. The encoded documents can be organized on several hierarchical SOMs, in which nearby locations contain similar documents (9)
}

1) create a matrix of descriptors considered as useful and relevant after discarding common and rare words from the corpus of words in sommelier comments. In this study 195 descriptors were selected from 2351words extracted from the original wine comments given for Marlborough 778 wines (for details on the text mining method (vector space model) see 9).

2) ascertain the correlations between descriptors/ groups of descriptors often used to describe different wine styles/ their ratings to select the high and low wine rate years for wine styles produced from the Marlborough region. The methods investigated in this research are: WEBSOM for grouping the co-occurring words (describing a feature) relating to wine style perhaps indicating high or low ratings. The Marlborough main wine styles being analysed in the paper are: Chardonnay, Pinot Noir, Riesling, Sauvignon Blanc, Pinot Gris and Gewürztraminer.

3) establish the correlations between style related descriptors and ratings using statistical methods

4) study the correlations between style related descriptors and ratings using data mining (DM) methods. The DM methods used in the research are: JRip and J48 (tree based) rule classification using WEKA software.

5) 254 Chardonnay vintages of New Zealand produced between 1996-2007 are studied to establish the wine descriptors related to the regions using statistical methods and then with data mining techniques.

\section{RESULTS}

Results obtained from different statistical and DM methods investigated to establish the correlations between wine descriptors and vintages of different NZ wine styles are discussed in this section

\section{1) The WEBSOM approach to Marlborough wine styles}

Using the WEBSOM approach word segments (features) relating to Marlborough vintages of different wine styles were initially analysed to establish the words (descriptors) that are correlated to the wine styles produced from this region.

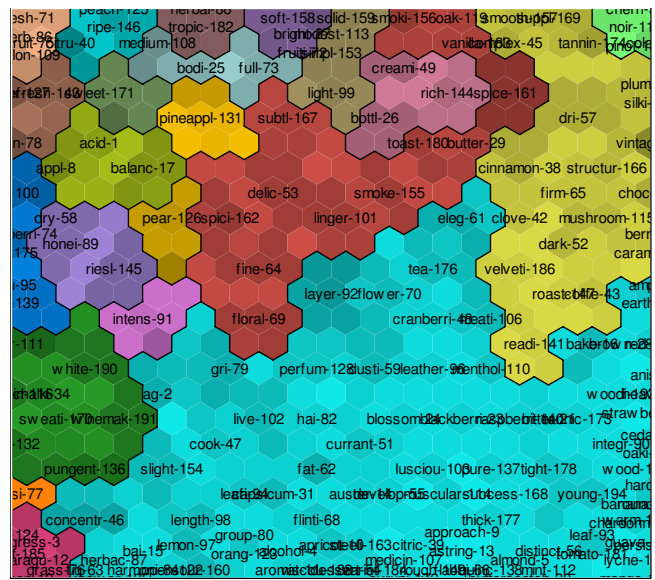

Figure 1. WEBSOM of 195 descriptors extracted from sommelier comments provided for 778 Marlborough vintages of styles produced from this famous wine region. The different segments in the SOM show the descriptors used to state the features (S1-S22) of the vintages by sommeliers. 

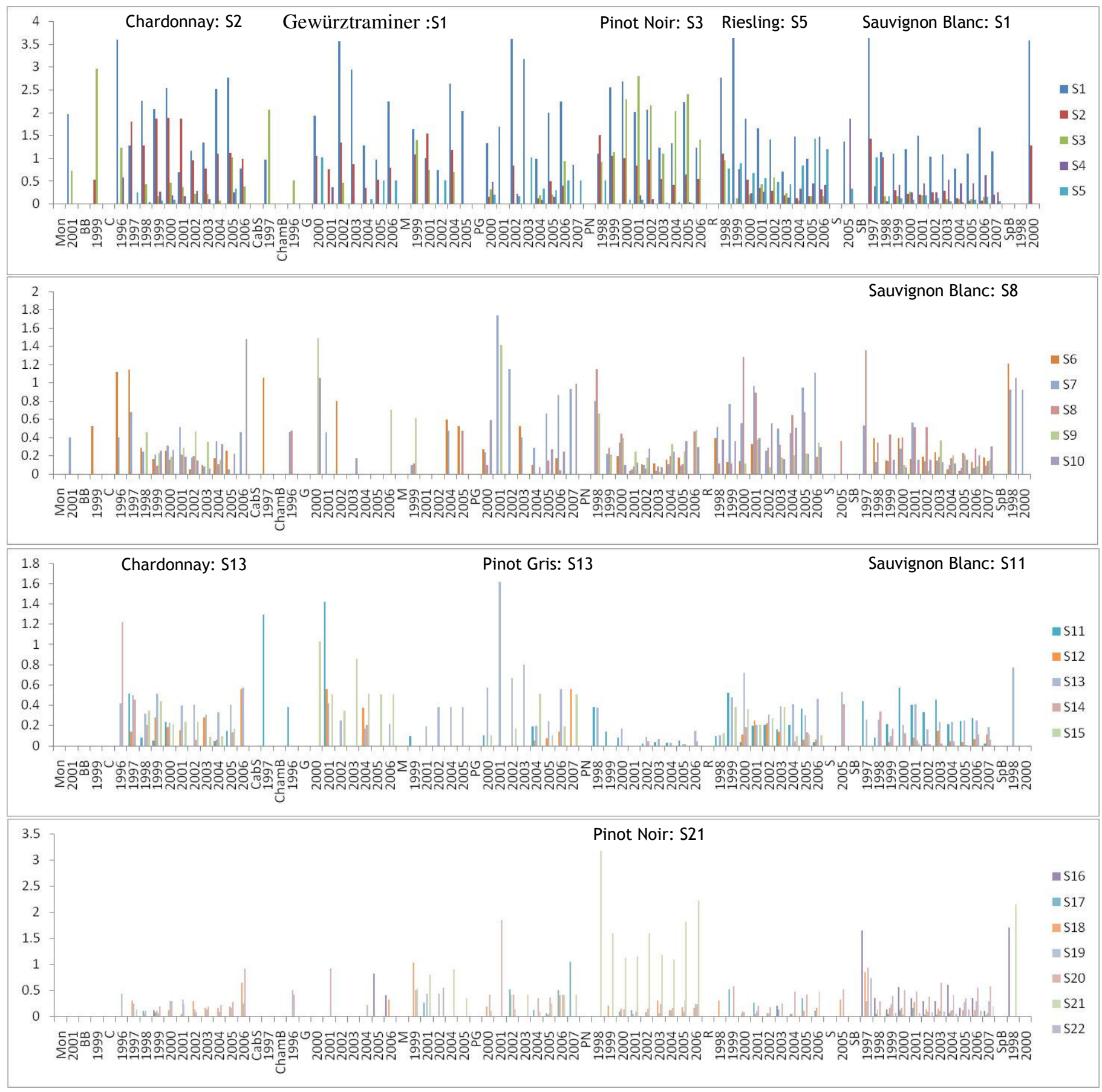

Figure 2. S1 (Sauvignon Blanc): eleg-61, tea-176, layer-92, flower-70, ampl6 earthi-60, cranberri-48, meati-106, bake-16, brown-28, red-142, gri-79, perfum-128, dusti-59, leather-96, menthol-110, ag-2, woodi-193, anis-7 heavi-85 strawberri-164, live-102, hai-82, blossom-24, blackberri-23, raspberri-140, bitter-21, tannic-173, cook-47, currant-51, integr-90, cedar-33 oaki-120, slight-154, fat-62, lusciou-103, pure-137, tight-178, wood-192, leafi-94, capsicum-31, auster-14, develop-55, muscular-114, success-168, young-194, hard-83 round-150, concentr-46, length-98, flinti-68, thick-177, warm-189, lemon-97, group-80 orang-123, apricot-10, steeli-163, citric-39, leaf-93 tomato-181, persist-129, fig-63, herbac-87 power-135, bai-15 harmoni-84 sharp-151, open-122, sour-160, alcohol-4 aromat-11 strong-165, viscou-188, dessert-54, variet-184, medicin-107 syrupi-172, rough-149, approach-9 astring-13 flabbi-66 fleshi-67 zesti195, quinc-138, almond-5 butterscotch-30, distinct-56 mint-112 nutti-118, banana-1 S2 (Chardonnay): smoki-156, oak-119, vanilla-183, spice-161, subtl-167, toast-180, butter-29, delic-53, smoke-155, spici-162, linger-101, fine-64, floral-69 (chardonnay) S3 (Pinot Noir): smooth-157, suppl-169, complex-45, tannin-174, plum-134 silki-152, dri-57, vintag-187, cinnamon-38, structur-166, firm-65, chocol-37, clove-42, mushroom-115, dark-52, berri-20 caramel-32, velveti-186, roast147, coffe-43, readi-141 S19: herbal-88 tropic-182 S20: clean-41 crisp-50 fresh-71 herb-86 melon-109, grapefruit-75 S21: black-22 cherri-36 noir-117 pinot-133, cola-44 S22: grassi-77 
The 22 word segments (figure 2) generated from the WEBSOM (figure 1) illustrate the correlations between the Marlborough wines styles and the wine descriptors (figure 2). The correlations were found between Chardonnay: S2, Pinot Noir: S3, Riesling: S5, Sauvignon Blanc: S1 Pinot Gris: S13 and Gewürztraminer: S1 descriptors. The 195 wine descriptors used were extracted from sommelier comments from a web magazine (http://buyingguide.winemag.com/regions/newzealand) for the vintages of 1996-2007 analysed in the study.

Based the DM results some descriptors can be attributed to certain styles. For example, either a) an higher weight of lychee or b) higher pear and spice along with low values of butter and ripe relate to Gewürztraminer style of Marlborough. Similarly, the descriptors and their respective weights relating to Marlborough's Pinot Noir, Pinot Gris, Riesling and Chardonnay are listed in Table 1. Anything that does not meet the conditions in the Table 1 is stated as Sauvignon Blanc (SB). Hence, to reveal the exact descriptors of SB, comments of SB vintages were analysed alone. Similarly, Chardonnay from all New Zealand regions during 1996 - 2006 were studied as an individual collection and the results are discussed in the next section.

\section{TABLE I. MARLBOROUGH VINTAGES (1997-2007) AND STYLES}

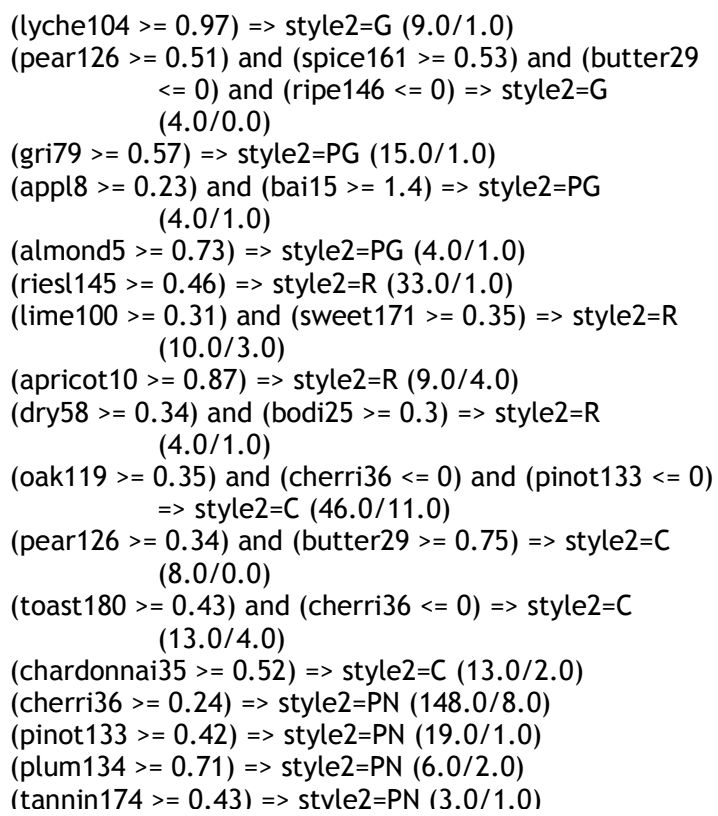

JRip rules (WEKA) show the correlations between the descriptors and Marlborough wine styles

TABLE II. MARLBOROUGH VINTAGE (1996-2006) DESCRIPTORS \& RATINGS

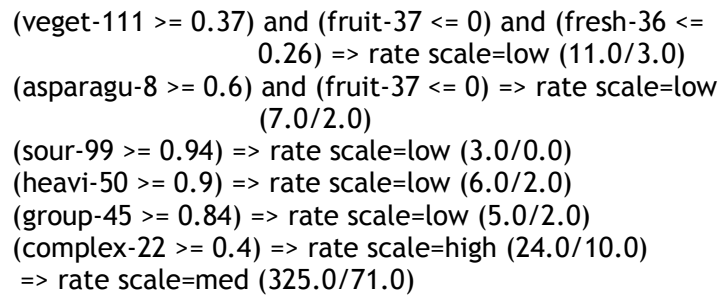

JRip rules show the correlations between Marlborough SB vintages and descriptors
2) Marlborough Sauvignon Blanc vintages and descriptors The collection of comments given for 381 Marlborough vintages was converted into matrix of 118 wine descriptors and their rates transformed into "low $<80$ " "medium (med) $>79$ and $<90$ " and "high $>89$ " based on their rating (100 point) for analysing with DM techniques using WEKA software. The JRip rules listed in Table II produced (at training 76\% and cross validation $70 \%$ ) for this indicate that high values of the descriptor veget (meaning vegetable 6 vegetal 26) and low values of fruit and fresh as related to "low" $(<80)$ rate in Marlborough SB vintages. Similarly, either higher weights of a) asparagus $(>=0.6)$ and fruit $(<=0)$ or b) high sour-99 $(0.94)$ or c) heavy ( $>=0.9)$ group $-45(>=0.84)$ are seen to be related to low rated SB vintages. On the other hand, high value of complex $(>=0.4)$ is related to higher ratings with an accuracy of 24.0 correct and 10.0 wrong.

TABLE III. RULES (J48) FOR MARLBOROUGH SB VINTAGES (19972007) \& RATINGS

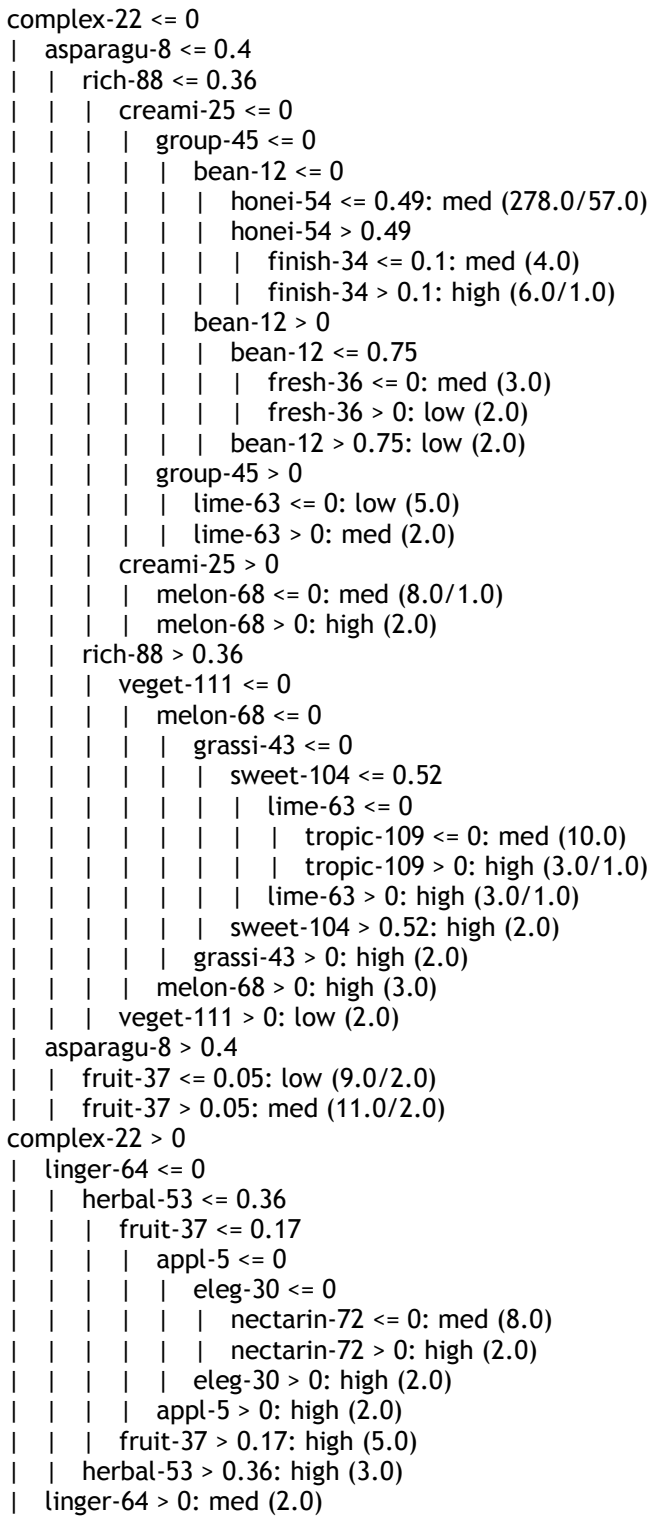


Meanwhile, classifier model created with $\mathrm{J} 48$ pruned trees (Table III, with WEKA, (training at $82 \%$ and cross validation at $67 \%$ )) produced rules with additional words (compared with that of the JRip) relating to rate classes (low, medium and high). The additional words included in J48 were: creami (creamy), bean, honei (honey), lime, melon, grassi (grassy), sweet, tropic, nectarine, eleg (elegant), apple, fruit, herbal, and linger.

\section{3) New Zeland's Chardonnay vintages and descriptors}

Finally, Chardonnay vintages produced from three regions of New Zealand (Gisborne, Waipara and Hawks' Bay) between 1996 and 2007 were analysed separately to identify the region related descriptors and their correlations between ratings as analysis conducted all the styles and vintages together using either WEBSOM descriptor groupings or JRip/ J48 model classifiers did not produce any interesting rules. The results obtained analysing the chardonnay vintages classified based on the regions produced interesting rules. The rules show the correlations between "low", "med" and "high" rate classes and are presented in Table IV.

TABLE IV. HAWK's BAY VINTAGES (1996-2006) AND DESCRIPTORS

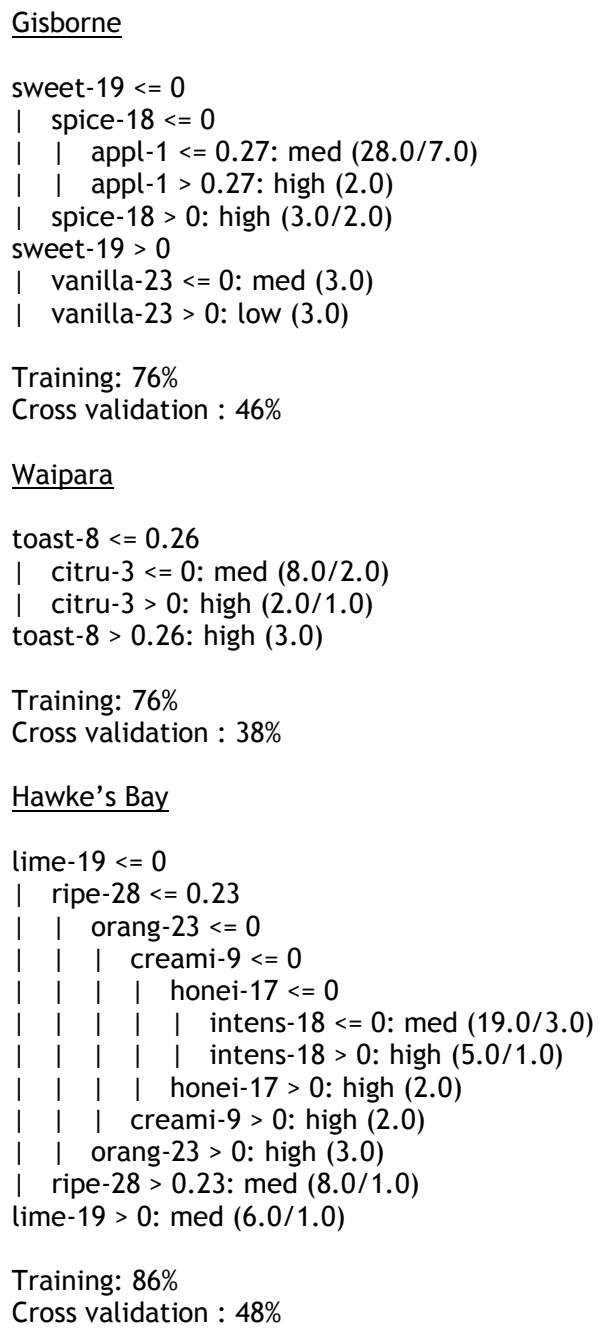

\section{CONCLUSIONS}

The paper illustrated statistical and data mining approaches investigated to establishing the correlations between wine descriptors (embedded in sommelier comments) and wine ratings in order to modelling the seasonal weather influences on New Zealand wine vintages. The results show potential for establishing the descriptors that can be used to characterise different wine styles, ratings and regions. The approaches can be further developed to find the identifying/ the special attributes in terms of wine descriptors, that could be used to relate wine style as well as quality i.e., ratings and then to model the seasonal weather variability and its effects on New Zealand vintage wines. The methods can as well provide a means to develop a viticulture zoning scheme as well as geographical indicators for New Zealand vintage wines.

\section{FUTURE WORK}

The research is on going and it is anticipated that once the specific descriptors for different wine styles, ratings and regions are identified and verified they could be incorporated into an GIS to model the climate as well as other local influences, such as environmental (soil, aspect, slope) at more finer scales, i.e., within vineyards on grapevine phenology and wine quality.

\section{ACKNOWLEDGMENT}

The authors wish to acknowledge the support extended by Master Winemaker Michael B of Kumeu River Wines and Peter Sumich of AUT.

\section{REFERENCES}

[1] Ashenfelter, O, Ashmore, D and Lalonde, R. Bordeaux Wine Vintage Quality and the Weather. Chance vol 8 No. 41995: 7-14., 1995.

[2] Shanmuganathan, S and Sallis, P. Modelling climate change effects on wine quality based on expert opinions expressed in free-text format: The WEBSOM Approach. ICONIP 2008, Part I, LNCS 5506, 2009. SpringerVerlag Berlin Heidelberg 2009. pp. 915-925. , 2009.

[3] Soar, C J, Sadras, V O and Petrie, P R. (2008) Climate drivers of red wine quality in four contrasting Australian wine regions. s.l. : Australian Journal of Grape and Wine Research 14, 78-90., 2008.

[4] Shanmuganathan, S. Viticultural zoning for the identification and characterisation of New Zealand "Terroirs" using cartographic data. in proceedings of GeoCart'2010 and ICA Symposium on Cartography () New Zealand Cartographic Society Inc, 2010 [Eds, 2010.

[5] Shanmuganathan, S., and Sallis, P. (2010). Determining the relationship between climate variations and wine quality: the WEBSOM approach. In Simard, S. (Ed), Climate Change and Variability, Sciyo, pp. 389-408, 2010.

[6] Shanmuganathan, S, Sallis, P and Narayanan, A. Data mining and X2 test based hybrid approach to modelling 
climate effects on grape crop in varieties of Kumeu, New Zealand in proceedings of [eds] Thatcher, S., 2011 3rd International Conference Conference on Machine Learning and Computing (ICMLC 2011) Singapore, 2628 February 2011, 978-1-4244-925 3-4 /11 C2011 IEEE Vol 1 pp 355-359, 2011.

[7] Shanmuganathan, S, Sallis, $\mathrm{P}$ and Narayanan, A.Data mining techniques for modelling seasonal climate effects on grapevine yield and wine quality in Second International Conference on Computational Intelligence, Communication Systems and Networks Networks (CICSyN), Liverpool, UK, 28 - 30 July, 84-89, 2010.

[8] van Leeuwen, Cornelis, Friant, Philippe, Chone, Xavier, Tregoat, Olivier, Koundouras, Stephanos, Dubourdieu, Denis. Influence of Climate, Soil, and Cultivar on Terroir. s.1. : 2004, Am. J. Enol. Vitic 2004 55:207-217., 2004.

[9] Jones, G V. Climate change: observations, projections, and general implications for viticulture and wine production. Practical Winery \& Vineyard: 44-64., 2007.

[10] Jones, G V and Davis, R E. Climate Influences on Grapevine Phenology, Grape Composition, and Wine Production and Quality for Bordeaux, France. Am. J. Enol. Vitic., Vol. 51, No.3, 2000 pp249-261. 2000.
[11] Shanmuganathan, S, Sallis, $P$ and Narayanan, A. Unsupervised artificial neural nets for modelling the effects of climate change on New Zealand grape wines. In B. Anderssen et al. (eds) /18th IMACS World Congress - MODSIM09 International Congress. s.1. : In B. Anderssen et al. (eds) /18th IMACS World Congress MODSIM09 International Congress on Modelling and Simulation/, 13-17 July 2009, Cairns, Australia. ISBN: 978-0-9758400-7-8. pp. 803-809., 2009.

[12] Honkela, T, et al. Self-organizing maps of very large document collections: Justification for the WEBSOM method. In Balderjahn, I., Mathar, R., and Schader, M., editors, Classification, Data Analysis, and Data Highways,. Springer, Berlin. pp 245-252. : http://lib.tkk.fi/Diss/2000/isbn9512252600/article4.pdf, 1998.

[13] Best, S, León, L and Claret, M. Use of Precision Viticulture Tools to Optimize the Harvest of High Quality Grapes in proceedings of Information and Technology for Sustainable Fruit and Vegetable Production FRUTIC 05, 12-16 September 2005, Montpellier France, 2005. http://www.symposcience.org/exl-doc/colloque/ART00001647.pdf. 